\title{
RELATIVE DISPLACEMENT RESPONSE SPECTRA WITH POUNDING EFFECT
}

\author{
Anat RUANGRASSAMEE ${ }^{1}$ And Kazuhiko KAWASHIMA ${ }^{2}$
}

\begin{abstract}
SUMMARY
To avoid unseating of a deck, an adequate seat length must be provided. The seat length is generally determined from a maximum relative displacement between two bridge segments. Under strong ground excitation, pounding between two decks may occur at a joint. The pounding will affect responses of two bridge segments. This research was conducted to investigate the effect of pounding on the relative displacement between two adjacent bridge segments. A simplified analytical model was developed for such a purpose. To take into account the pounding, the laws of conservation of momentum and energy were applied. The analytical results were represented in the form of a relative displacement response spectrum with pounding effect. It is found that due to the pounding the relative displacement can be amplified, resulting in the requirement of a longer seat length to support a deck.
\end{abstract}

\section{INTRODUCTION}

In the morning of January 17, 1995, the Hyogo-ken Nanbu earthquake endangered human life and caused devastative damage to civil engineering structures in the vicinity of Kobe City. According to the investigation, it was found that many bridges suffered unseating of decks from piers. The unseating of bridge decks is considered as an undesirable performance of bridges because it leads to the loss of function and harms the safety of human life. After the occurrence of an earthquake, an important bridge treated as a main lifeline for emergent transportation is expected to withstand and be able to serve its functions. To meet the requirement, many researchers have so far developed preventing and retrofitting procedures to prevent the unseating of the bridge decks. One approach is to provide an adequate seat length on a pier top to support a deck. The key parameter to determine the seat length is the maximum relative displacement developed between two adjacent bridge segments. If the provided seat length is larger than the maximum relative displacement developed during strong ground excitation, it is assured that the deck will not unseat from the pier. Kawashima and Sato (1996) proposed a method to predict the maximum relative displacement between two bridge segments with different natural periods. It was proposed to call a relative displacement response spectrum from its analogy to a displacement response spectrum. In actual situations, the problem of the unseating is made complicated by the fact that the gap provided to separate two bridge segments at a hinge may be smaller than the maximum relative displacement. Consequently, pounding will occur unavoidably. The pounding will affect responses of two bridge segments. The pounding effect on dynamic responses of buildings and bridges has been studied by many researchers. However, the scopes of those investigations were limited on analyses of some particular structures. The effect of the pounding has not been generalized in a rational way.

This research was conducted to investigate the effect of pounding on the relative displacement between two adjacent structures. A simplified analytical model was developed for such a purpose. The results from series of analyses were presented in the form of a response spectrum, called as a relative displacement response spectrum with pounding effect. It is a rational way to represent the effect of pounding on the relative displacement. 


\section{ANALYTICAL PROCEDURES}

\section{Analytical Model}

To investigate dynamic responses of a bridge with the consideration of pounding, a simplified analytical model was developed. Two bridge segments connected at a joint were idealized as two equivalent-linear single-degreeof-freedom systems as shown in Figure 1. The systems are referred to as System 1 and System 2. Systems 1 and 2 are separated by a gap $\Delta_{\mathrm{G}}$. Two systems are subjected to the same ground motion, neglecting spatial variation of ground motions along the longitudinal direction of the bridge. The natural periods of Systems 1 and 2 are denoted as $T_{1}$ and $T_{2}$, respectively. The damping ratios of Systems 1 and 2 are defined as $h_{1}$ and $h_{2}$, respectively. The lumped mass of System 1 is $\mathrm{m}_{1}$, and that of System 2 is $\mathrm{m}_{2}$. To account for the pounding between Systems 1 and 2, the laws of conservation of momentum and energy were applied. As shown in Figure 1, the displacement responses without pounding of Systems 1 and 2 are defined as $u_{1}(t)$ and $u_{2}(t)$, respectively. The displacement responses with pounding of Systems 1 and 2 are defined as $u_{1}^{p}(t)$ and $u_{2}^{p}(t)$, respectively.

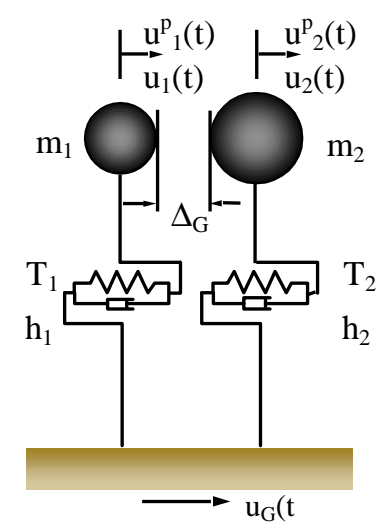

Figure 1: Idealized model

\section{Modeling of Pounding}

In this investigation, the pounding between Systems 1 and 2 was taken into account by the application of the classical theory of impact. The theory is based on the laws of conservation of momentum and energy. An impact may be defined as a sudden contact between two bodies involving large contact force acting for a short time. Consider two bodies of mass $\mathrm{m}_{1}$ and $\mathrm{m}_{2}$ in rectilinear motion that come into contact with velocities $\mathrm{V}_{1}$ and $\mathrm{V}_{2}$. The sign of velocities is taken as positive to the right. This form of impact is called a direct central impact [Goldsmith, 1960]. All external forces during impact are neglected. Velocities of two bodies after impact are obtained as follows

$$
\begin{aligned}
& V_{1}^{\prime}=V_{1}-(1+e) \frac{m_{2}\left(V_{1}-V_{2}\right)}{m_{1}+m_{2}} \\
& V_{2}^{\prime}=V_{2}+(1+e) \frac{m_{1}\left(V_{1}-V_{2}\right)}{m_{1}+m_{2}}
\end{aligned}
$$

where $V_{1}^{\prime}$ and $V_{2}^{\prime}$ are the velocities after impact of $\mathrm{m}_{1}$ and $\mathrm{m}_{2}$, respectively and $e$ is a coefficient of restitution of a material. The value of $e$ ranges from 0 to 1.0. If $e=1.0$, no energy loss occurs in the impact. But energy loss becomes maximum for $e=0$. Eqs. (1) and (2) were employed in the analysis to compute the velocities after pounding from the known velocities before pounding.

\section{Computational Method}

The governing equation of the analytical model is expressed as follows:

$m_{i} \ddot{u}_{i}^{p}(t)+c_{i} \dot{u}_{i}^{p}(t)+k_{i} u_{i}^{p}(t)=\ddot{u}_{G}(t)$

where $\mathrm{i}$ denotes the system under consideration, that is System 1 or System 2. The displacement responses $u_{1}^{p}(t)$ and $u_{2}^{p}(t)$ are obtained numerically by using the fourth-order Runge-Kutta Method. The normal time interval of numerical computation is set equal to the time interval of a ground motion record. The displacement responses $u_{1}^{p}(t)$ and $u_{2}^{p}(t)$ at any time $t$ are computed and the occurrence of pounding is checked according to the following condition: 
$u_{1}^{p}(t)-u_{2}^{p}(t) \geq \Delta_{G}$

If the above condition is satisfied, it means that pounding occurs in that time step. So, the time that pounding occurs, $t_{p}$, is evaluated by interpolating to find the time that the displacements satisfy the following condition:

$u_{1}^{p}\left(t_{p}\right)-u_{2}^{p}\left(t_{p}\right)=\Delta_{G}$

Then the velocities of Systems 1 and 2 at the time $t_{p}$ are input in Eqs. (1) and (2) to determine the velocities after pounding. And the velocities after pounding are used for re-evaluating the displacements and velocities at the time $t$. Then, the computation continues with the normal time interval. The conceptual illustration of the computation is shown in Figure 2. It is worthy to note that the duration of pounding is neglected in the computation.

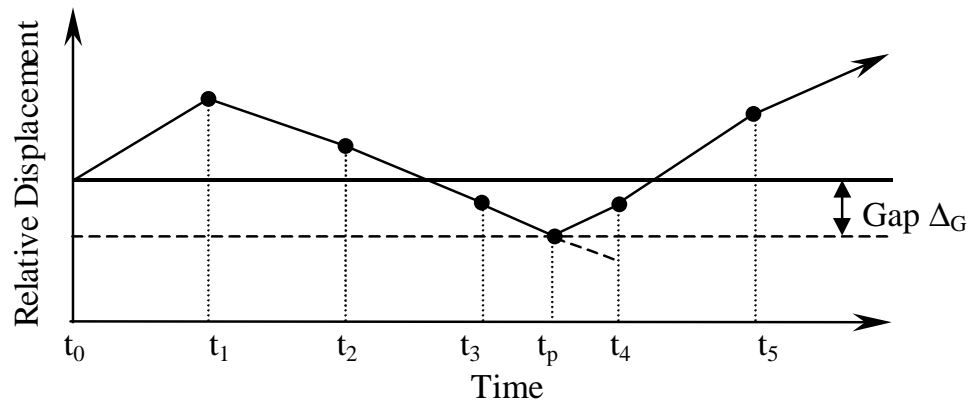

Figure 2: Time intervals for numerical computation

\section{Parameters in Analysis}

In this analysis, the natural periods of Systems 1 and $2\left(\mathrm{~T}_{1}\right.$ and $\left.\mathrm{T}_{2}\right)$ were varied from 0.05 to 3.00 sec with an increment of $0.05 \mathrm{sec}$ to cover the typical range of fundamental natural periods of highway bridges. A viscous damping ratio of 0.05 was applied for both systems. The value of the damping ratio is typical for reinforcedconcrete structures of moderate sizes. The coefficient of restitution $e$ was assumed equal to 1.0, neglecting energy loss in pounding. The mass $\mathrm{m}_{1}$ and $\mathrm{m}_{2}$ were assumed the same. The analytical results from 2 ground motions will be presented in this paper. Figure 3(a) shows the time history of the N-S component of the freefield ground motion recorded at the JMA observatory in Kobe in the 1995 Hyogo-ken Nanbu earthquake. The earthquake had a magnitude of 7.2. Hereafter the ground motion will be referred to as the JMA Kobe record. The peak ground acceleration of the JMA Kobe record was 0.83 g. Figure $3(\mathrm{~b})$ shows the time history of the N-S component of the free-field ground motion recorded at Sylmar in the 1994 Northridge earthquake. The earthquake had a magnitude of 6.7. The ground motion will be referred to as the Sylmar record. The peak ground acceleration of the Sylmar record was $0.84 \mathrm{~g}$.
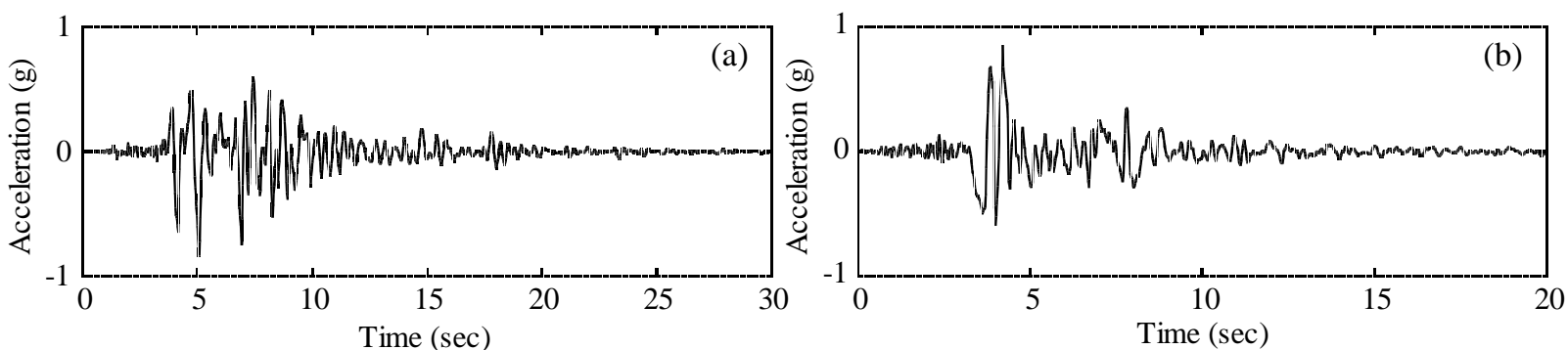

Figure 3: The JMA Kobe record (a) and the Sylmar record (b)

\section{NORMALIZATION OF PARAMETERS}

It is obvious that if the gap $\Delta_{\mathrm{G}}$ separating Systems 1 and 2 is sufficiently large, the pounding will not occur. The minimum gap required to prevent pounding can be determined from the maximum relative displacement of System 1 to System 2, that is $\left[u_{1}(t)-u_{2}(t)\right]_{M A X}$. The gap will be referred to as a critical gap. If the gap is smaller than the critical gap, the pounding will occur unavoidably. A seat length is evaluated from the maximum relative displacement of System 2 to system 1, that is $\left[u_{2}(t)-u_{1}(t)\right]_{M A X}$ for the case of no pounding or $\left[u_{2}^{p}(t)-u_{1}^{p}(t)\right\rfloor_{\text {MAX }}$ for the case of pounding. Hereafter, the maximum relative displacement of System 2 to System 1 with or without pounding will be referred shortly as the maximum relative displacement. 
In this study, the main objective is put towards the investigation of the effect of pounding on the relative displacement between two bridge segments. It can be seen that the normalization of some key parameters will lead to the meaningful interpretation of analytical results. The gap $\Delta_{\mathrm{G}}$ is normalized as:

$r_{G}=\frac{\Delta_{G}}{\left[u_{1}(t)-u_{2}(t)\right]_{M A X}}$

The parameter $r_{G}$ will be referred to as a gap ratio. If the value of $r_{G}$ is equal to or larger than 1.0, the pounding does not occur. But if the value of $\mathrm{r}_{\mathrm{G}}$ is smaller than 1.0, the pounding occurs. In this analysis, the gap ratio $\mathrm{r}_{\mathrm{G}}$ was varied from 0 to 1.0 with an increment of 0.1 .

The maximum relative displacement is normalized as:

$r_{R D}=\frac{\left[u_{2}^{p}(t)-u_{1}^{p}(t)\right]_{M A X}}{\left[u_{2}(t)-u_{1}(t)\right]_{M A X}}$

The parameter $\mathrm{r}_{\mathrm{RD}}$ will be referred to as a relative displacement ratio. The value of $\mathrm{r}_{\mathrm{RD}}$ represents the amplification of the maximum relative displacement due to pounding. If $\mathrm{r}_{\mathrm{G}}$ is equal to or larger than 1.0, $\mathrm{r}_{\mathrm{RD}}$ is equal to 1.0, showing no pounding and no amplification of the maximum relative displacement. If $r_{\mathrm{G}}$ is less than $1.0, \mathrm{r}_{\mathrm{RD}}$ may be smaller or larger than 1.0 because of the effect of pounding. It is worthy to point out that the normalization advantageously eliminates the effect of peak ground acceleration of a ground motion.

\section{THE EFFECT OF POUNDING ON DYNAMIC RESPONSES}

Consider the case of $\mathrm{T}_{1}=0.80 \mathrm{sec}$ and $\mathrm{T}_{2}=2.00 \mathrm{sec}$. Figure 4(a) shows dynamic responses without pounding of Systems 1 and 2. It is found that a maximum relative displacement is equal to $0.41 \mathrm{~m}$. A critical gap is $0.46 \mathrm{~m}$. If the gap provided between two systems is equal to or larger than $0.46 \mathrm{~m}$, the pounding does not occur. But if the gap is less than $0.46 \mathrm{~m}$, the pounding will occurs unavoidably. Figure 4(b) illustrates dynamic responses with pounding. The gap $\Delta_{\mathrm{G}}$ is set to $0.23 \mathrm{~m}$, corresponding to a gap ratio $\mathrm{r}_{\mathrm{G}}$ of 0.5 . It is seen that the relative displacement in the negative side is limited to be equal to the gap of $0.23 \mathrm{~m}$. Comparing the relative displacement without pounding to that with pounding, it is obvious that the pounding causes increase in the relative displacement. The maximum relative displacement is $0.85 \mathrm{~m}$, resulting in the relative displacement ratio of 2.1 .
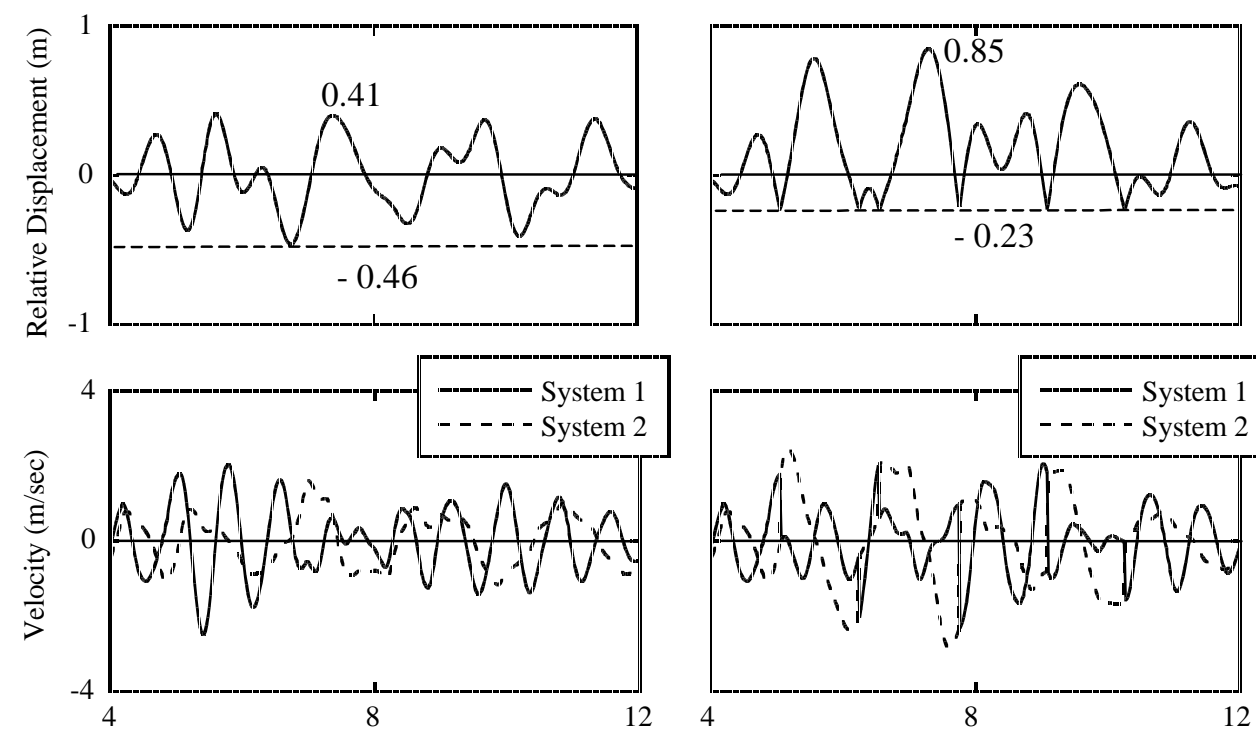

(a) Time (sec)

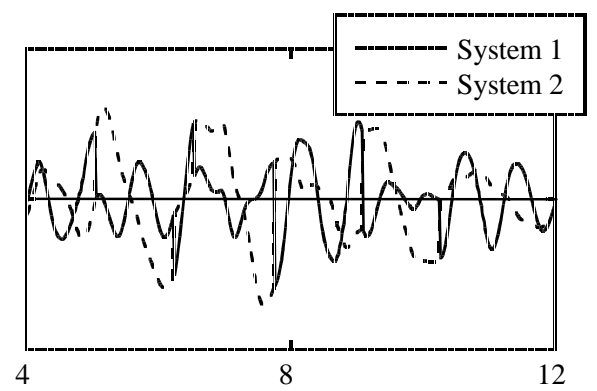

(b) Time (sec)

Figure 4: Dynamic responses without pounding (a) and with pounding (b)

Figure 5 presents maximum relative displacements for various gaps. It is seen that for a gap equal to or larger than the critical gap of $0.46 \mathrm{~m}$, the maximum relative displacement is constant and equal to $0.41 \mathrm{~m}$. Increase of the maximum relative displacement is observed when the gap is less than the critical gap. Figure 6 shows relative displacement ratio $\mathrm{r}_{\mathrm{RD}}$ versus gap ratio $\mathrm{r}_{\mathrm{G}}$. For $\mathrm{r}_{\mathrm{G}} \quad 1.0, \mathrm{r}_{\mathrm{RD}}$ is equal to 1.0, showing that there is no effect of pounding on the relative displacement. For $\mathrm{r}_{\mathrm{G}}<1.0, \mathrm{r}_{\mathrm{RD}}$ is larger than 1.0. It means that the effect of pounding is significant, resulting in the increase of the maximum relative displacement. It is seen that $\mathrm{r}_{\mathrm{RD}}$ takes the maximum value at a certain $\mathrm{r}_{\mathrm{G}}$. The maximum value of $\mathrm{r}_{\mathrm{RD}}$ is 2.1 at $\mathrm{r}_{\mathrm{G}}=0.5$. 

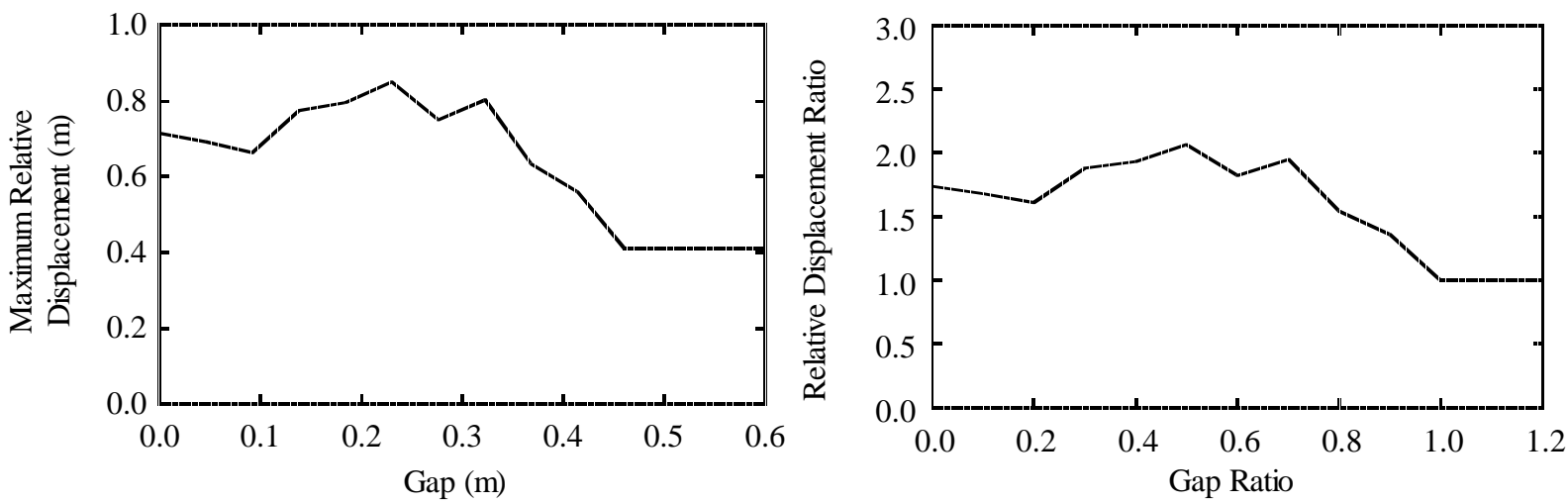

Figure 5: Maximum relative displacement vs. gap Figure 6: Relative displacement ratio vs. gap ratio

\section{ANALYTICAL RESULTS AND DISCUSSIONS}

If the maximum relative displacement for a specific gap ratio is evaluated for various combinations of $\mathrm{T}_{1}$ and $\mathrm{T}_{2}$, a representation can be made in the form of a response spectrum. The representation is proposed to call a relative displacement response spectrum $\mathrm{RD}\left(\mathrm{T}_{1}, \mathrm{~T}_{2}\right)$ for $\mathrm{r}_{\mathrm{G}} \quad 1.0$ or a relative displacement response spectrum with pounding effect $\operatorname{RDP}\left(\mathrm{T}_{1}, \mathrm{~T}_{2}\right)$ for $\mathrm{r}_{\mathrm{G}}<1.0$. The relative displacement response spectrum of the JMA Kobe record is shown in Figure 7. The relative displacement response spectrum with pounding effect of the JMA Kobe record for $\mathrm{r}_{\mathrm{G}}=0.5$ is shown in Figure 8. In the same manner, if the relative displacement ratio for a specific gap ratio is evaluated for various combinations of $\mathrm{T}_{1}$ and $\mathrm{T}_{2}$, a representation can be made in the form of a response spectrum. The representation is proposed to call a relative displacement ratio response spectrum $\mathrm{r}_{\mathrm{RD}}\left(\mathrm{T}_{1}, \mathrm{~T}_{2}\right)$. The relative displacement ratio response spectrum of the JMA Kobe record for $r_{G}=0.5$ is shown in Figure 9.

From the definition of the relative displacement response spectrum, $R D\left(T_{1}=0, T_{2}\right)$ or $R D\left(T_{1}, T_{2}=0\right)$ is equivalent to a displacement response spectrum. The relative displacement at $T_{1}=T_{2}$ is equal to zero. Since systems with the same natural periods vibrate in-phase, there is no separation between the systems. It can be seen that $\mathrm{RD}\left(\mathrm{T}_{1}, \mathrm{~T}_{2}\right)$ is more or less symmetric about the line $\mathrm{T}_{1}=\mathrm{T}_{2}$. However, it is not absolutely symmetry because of the unsymmetry of ground excitation.

Comparing $\operatorname{RD}\left(\mathrm{T}_{1}, \mathrm{~T}_{2}\right)$ with $\operatorname{RDP}\left(\mathrm{T}_{1}, \mathrm{~T}_{2}\right)$, it is obvious that the pounding results in increases and decreases in relative displacements at some combinations of $T_{1}$ and $T_{2}$. Like $\operatorname{RD}\left(T_{1}, T_{2}\right), \operatorname{RDP}\left(T_{1}, T_{2}\right)$ is more or less symmetric about the line $\mathrm{T}_{1}=\mathrm{T}_{2}$. However, it is not absolutely symmetry because of the unsymmetry of ground excitation. It should be noted that along the line $T_{1}=T_{2}, R D\left(T_{1}, T_{2}\right)$ is equal to zero, making $r_{R D}\left(T_{1}, T_{2}\right)$ undetermined. It causes the discontinuity of $r_{R D}\left(T_{1}, T_{2}\right)$ along the line $T_{1}=T_{2}$. However, $r_{R D}\left(T_{1}, T_{2}\right)$ represented here is made continuous by connecting $r_{R D}\left(T_{1}, T_{2}\right)$ for $T_{1}>T_{2}$ and $r_{R D}\left(T_{1}, T_{2}\right)$ for $T_{1}<T_{2} . r_{R D}\left(T_{1}, T_{2}\right)$ for $r_{G}=1.0$ is equal to 1.0 for all combinations of $\mathrm{T}_{1}$ and $\mathrm{T}_{2}$ because there is no pounding.

As seen from Figure 9, it is obvious that for almost all combinations of $T_{1}$ and $T_{2}, r_{R D}\left(T_{1}, T_{2}\right)$ is larger than 1.00. It means that the effect of pounding on the relative displacement is significant, resulting in the increase of the maximum relative displacement. The general trend of $r_{R D}\left(T_{1}, T_{2}\right)$ is that $r_{R D}\left(T_{1}, T_{2}\right)$ increases as the difference between $T_{1}$ and $T_{2}$ increases. It shows that the effect of pounding on the maximum relative displacement is significant for the systems with largely different natural periods. The pounding may cause the maximum relative displacement to increase up to about 3 times. Figure 10 illustrates $r_{R D}\left(T_{1}, T_{2}\right)$ for $r_{G}=0.2,0.7$, and 0.9 . It is seen that the general trend of $\mathrm{r}_{\mathrm{RD}}\left(\mathrm{T}_{1}, \mathrm{~T}_{2}\right)$ remains unchanged for other $\mathrm{r}_{\mathrm{G}}$. However, local variations can be observed at any combination of $\mathrm{T}_{1}$ and $\mathrm{T}_{2}$. It is found that $\mathrm{r}_{\mathrm{RD}}\left(\mathrm{T}_{1}, \mathrm{~T}_{2}\right)$ tends to decrease as $\mathrm{r}_{\mathrm{G}}$ increases. As mentioned above, $r_{R D}\left(T_{1}, T_{2}\right)$ becomes equal to 1.0 for $r_{G}$ equal to or larger than 1.0. Figure 11 shows $r_{R D}\left(T_{1}, T_{2}\right)$ of the Sylmar record for $r_{G}=0.5$. Comparing $r_{R D}\left(T_{1}, T_{2}\right)$ of the Sylmar record with that of the JMA Kobe record, it is obvious that $\mathrm{r}_{\mathrm{RD}}\left(\mathrm{T}_{1}, \mathrm{~T}_{2}\right)$ of the Sylmar record is smaller and close to 1.0 in almost all combinations of $\mathrm{T}_{1}$ and $\mathrm{T}_{2}$. It means that the effect of pounding is not significant for the Sylmar record. It is evident that the relative displacement response spectra with pounding effect highly depends on the characteristics of ground motions. 


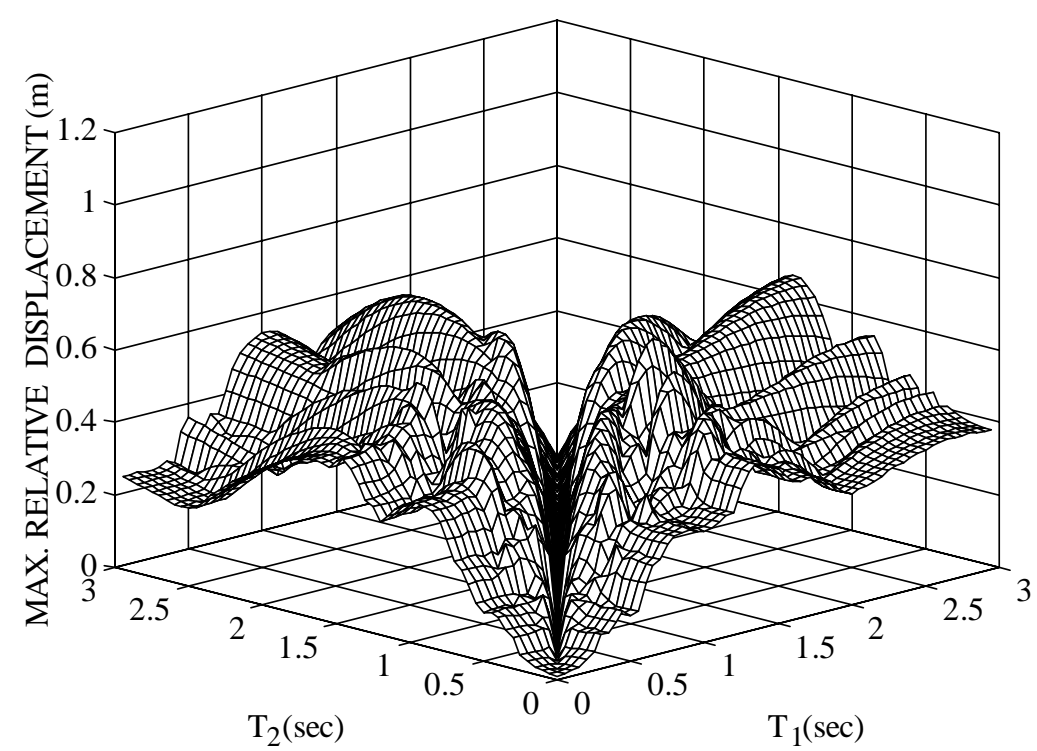

Figure 7: Relative displacement response spectrum of JMA Kobe record

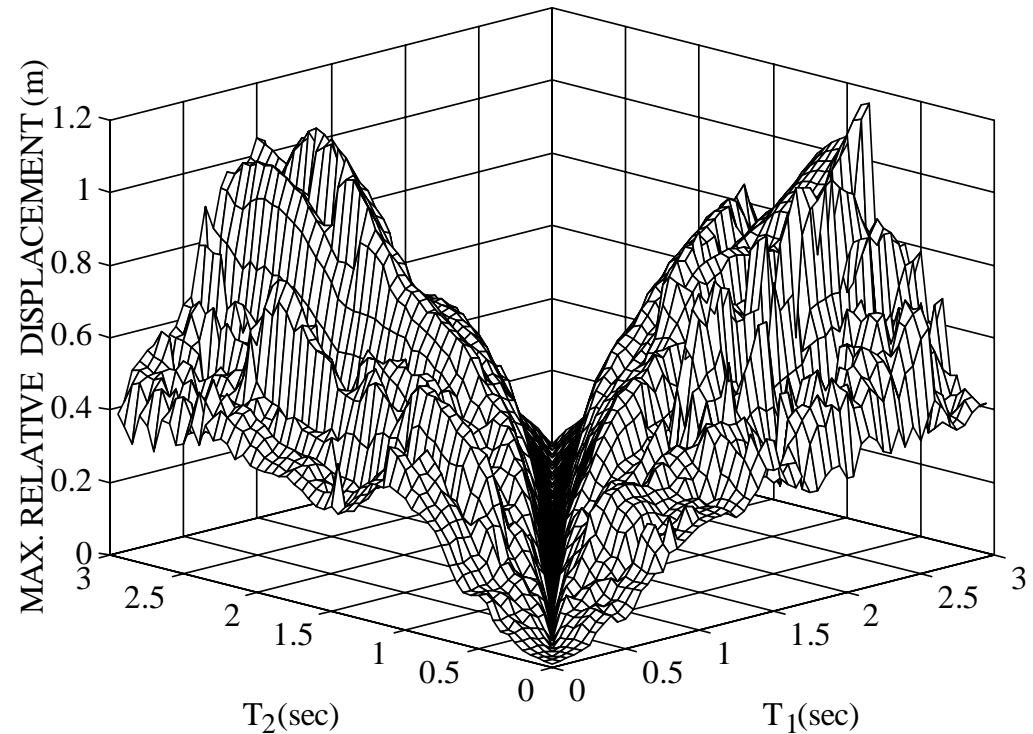

Figure 8: Relative displacement response spectrum with pounding effect of JMA Kobe record $\left(r_{G}=0.5\right)$

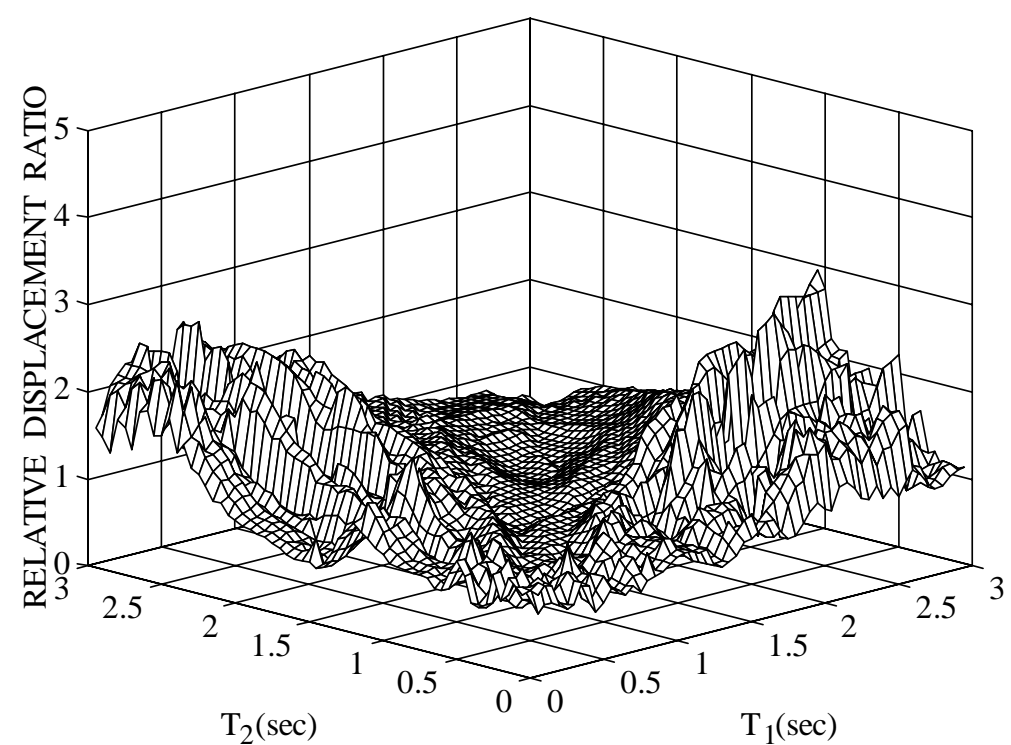

Figure 9: Relative displacement ratio response spectrum of JMA Kobe record $\left(r_{G}=0.5\right)$ 


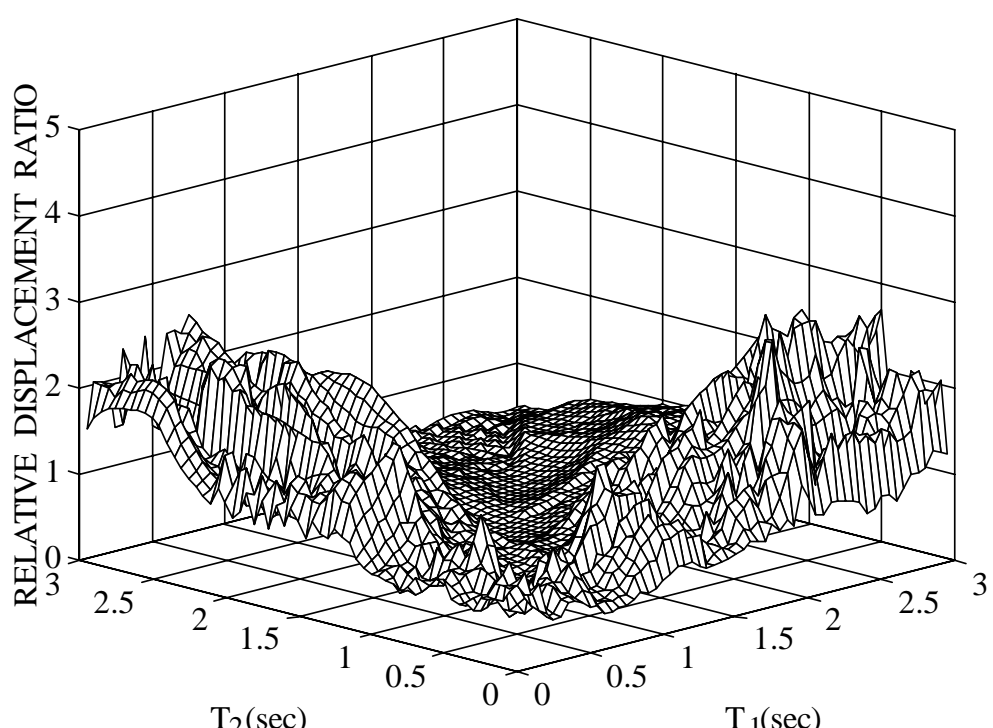

(a)

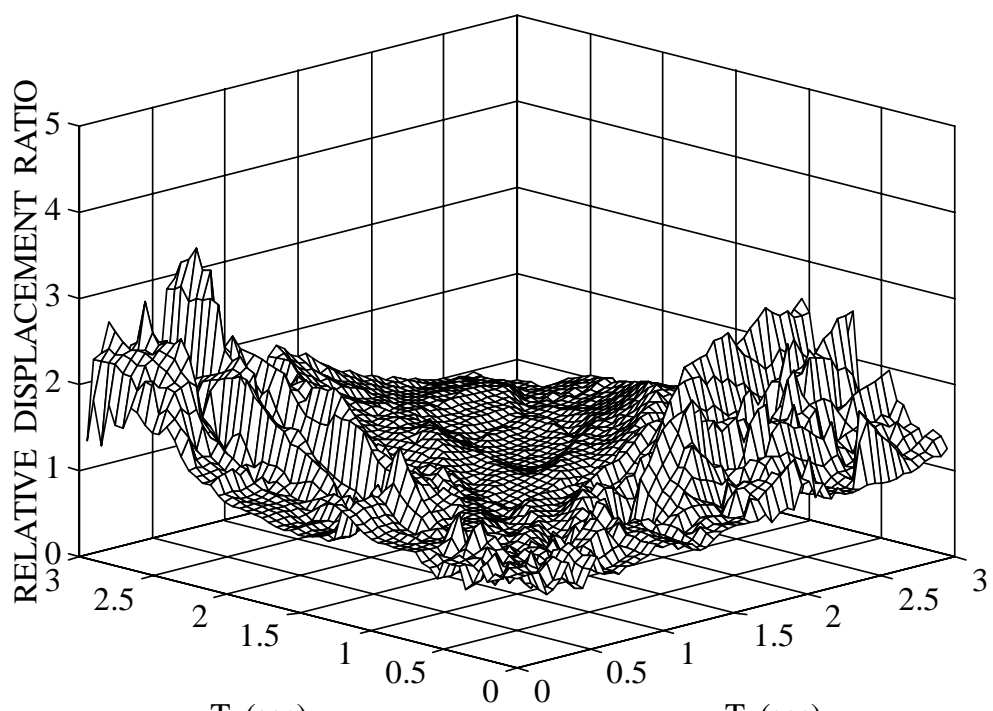

(b)

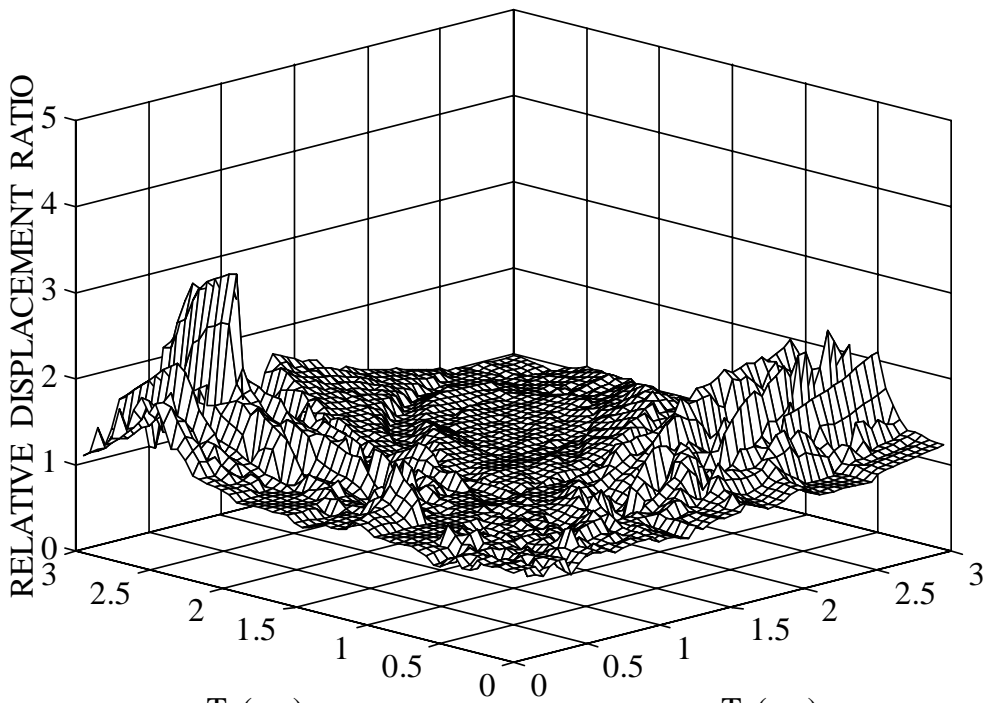

$\mathrm{T}_{2}$ (sec)

(c)

Figure 10: Relative displacement ratio response spectrum of the JMA Kobe record for (a) $\mathrm{r}_{\mathrm{G}}=0.2$, (b) $\mathrm{r}_{\mathrm{G}}=0.7$, and (c) $\mathrm{r}_{\mathrm{G}}=0.9$ 


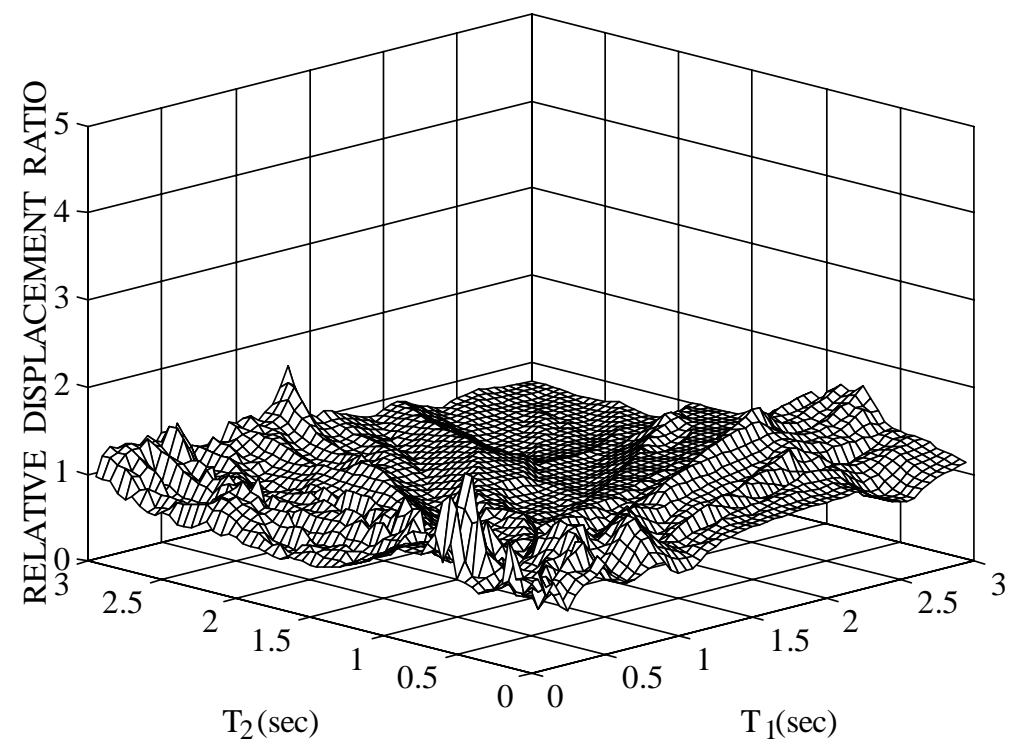

Figure 11: Relative displacement ratio response spectrum of the Sylmar $\operatorname{record}\left(r_{G}=0.5\right)$

\section{CONCLUSIONS}

To evaluate the effect of pounding on the maximum relative displacement between two bridge segments with different natural periods, the relative displacement response spectra with pounding effect were proposed. The effect of pounding on the maximum relative displacement was observed for various combinations of natural periods and gaps. The analytical results from 2 ground motion records are presented in this paper. Based on the analytical results, it can be concluded that:

1) The pounding leads to the amplification of maximum relative displacement between two bridge segments connected at a joint. Consequently, to withstand the effect of pounding, a longer seat length should be provided to support a deck. And the value of the adequate seat length can be realized by the application of the relative displacement response spectra with pounding effect.

2) The amplification of maximum relative displacement tends to decreases as the gap between two bridge segments increases.

3) The relative displacement ratio response spectra are highly dependent on the characteristics of ground motions. Consequently, the effect of ground motion characteristics deserves the further investigation.

\section{REFERENCES}

Goldsmith, W. (1960), Impact, Edward Arnold, London, UK.

Japan Road Association (1996), Part V Seismic Design - Design Specifications of Highway Bridges, Tokyo, Japan

Kawashima, K. and Sato, T. (1996), "Relative displacement response spectrum and its application", Proceedings 11 WCEE, 1103, Acapulco, Mexico. 